\title{
A retrospective study of late adverse events in proton beam therapy for prostate cancer
}

\author{
HIROKAZU MAKISHIMA, HITOSHI ISHIKAWA, KEIICHI TANAKA, YUTARO MORI, MASASHI MIZUMOTO, \\ KAYOKO OHNISHI, TERUHITO AIHARA, NOBUYOSHI FUKUMITSU, \\ TOSHIYUKI OKUMURA and HIDEYUKI SAKURAI
}

Department of Radiation Oncology and Proton Medical Research Center, University of Tsukuba, Tsukuba, Ibaraki 305-8576, Japan

Received February 23, 2017; Accepted August 3, 2017

DOI: $10.3892 / \mathrm{mco} .2017 .1372$

\begin{abstract}
The efficacy and safety of proton beam therapy (PBT) were retrospectively evaluated in 111 consecutive patients with prostate cancer who underwent definitive PBT between 2008 and 2012. Following exclusion of 18 patients due to treatment suspension, loss to follow-up, and histology, the analysis included 93 patients with a median age of 68 years (range, 49-81 years). A total of 7, 32 and 54 prostate cancer patients were classified as low-, intermediate- and high-risk, respectively, as follows: High-risk, $\mathrm{T} \geq 3$ a or prostate-specific antigen $(\mathrm{PSA}) \geq 20 \mathrm{ng} / \mathrm{ml}$ or Gleason Score $\geq 8$; low-risk, $\mathrm{T} \leq 2 \mathrm{~b}$ and $\mathrm{PSA} \leq 10 \mathrm{ng} / \mathrm{ml}$ and Gleason Score=6; intermediate-risk, all other combinations. The median initial prostate-specific antigen (PSA) level was $9.75 \mathrm{ng} / \mathrm{ml}$ (range, 1.4-100 ng/ml) and the median Gleason score was 7 (range, 6-10). Patients with low-risk disease received $74 \mathrm{GyE}$ (relative biological effectiveness $=1.1$ ) in 37 fractions, and those at intermediate or higher risk received $78 \mathrm{GyE}$ in 39 fractions. Complete androgen blockade $(\mathrm{CAB})$ therapy was performed from 6 months prior to PBT for patients with intermediate- or high-risk disease. $\mathrm{CAB}$ was continued during PBT and then terminated at the end of PBT for intermediate-risk patients. Patients at high risk continued $\mathrm{CAB}$ for 3 years. No combination therapy was used for low-risk patients. All the patients were followed up for $>2$ years after PBT, and all but one were PSA failure-free. The Common Terminology Criteria for Adverse Events v.4.0 was used to evaluate late adverse events. One patient developed grade 3 non-infectious cystitis and hematuria. Grade 2 urinary frequency was observed in 1 patient, and grade 2 rectal bleeding occurred in 4 patients. Of the 4 patients with grade 2 rectal bleeding, 2 received anticoagulant therapy, but none
\end{abstract}

Correspondence to: Dr Hirokazu Makishima, Department of Radiation Oncology and Proton Medical Research Center, University of Tsukuba, 2-1-1 Amakubo, Tsukuba, Ibaraki 305-8576, Japan E-mail: maxima@pmrc.tsukuba.ac.jp

Key words: prostate cancer, proton therapy, radiotherapy, particle therapy, dose volume histogram analysis, late adverse events had diabetes mellitus or another high-risk comorbidity. The median time to occurrence of an adverse event of grade $\geq 2$ was 14 months (range, 3-41 months). Therefore, the present retrospective study revealed that PBT at 78 GyE/39 Fr was well-tolerated and achieved good tumor control in patients with prostate cancer.

\section{Introduction}

Radiation therapy is standard treatment for localized prostate cancer, but late adverse events, such as rectal bleeding, are a major concern, with a reported risk of 5-20\% for genitourinary (GU) and gastrointestinal (GI) adverse events of grade $\geq 2(1,2)$. The irradiated dose and volume to an organ at risk (OAR) are correlated with the frequency of late adverse events $(1,3)$, but higher local doses also achieve better local control $(4,5)$. Thus, a high radiation dose to the target and reduction of OAR doses are critical factors in radiation therapy. The emergence of image-guided radiotherapy (IGRT), 3-dimentional conformal radiotherapy (3D-CRT), and its successor, intensity-modulated radiotherapy (IMRT), has significantly lowered toxicity to the bladder and rectum, although $5-10 \%$ of the patients develop grade 2 or more severe toxicity (5-7).

Charged particle beams, such as those used in proton beam therapy (PBT), deliver high radiation doses to the target in a conformal manner, which minimizes the doses to OARs. These advantages are based on the fundamental physical dose distribution of charged particle beams (8). However, the number of clinical trials on PBT for prostate cancer is limited. A dose escalation study using PBT as a boost yielded favorable results (9), but with limited follow-up of patients who received PBT alone. We herein report a retrospective review of the efficacy and safety of PBT for prostate cancer.

\section{Patients and methods}

Patients. A total of 111 consecutive patients underwent definitive PBT for prostate cancer at the Department of Radiation Oncology and Proton Medical Research Center (Tsukuba, Japan) between 2008 and 2012. A total of 11 patients were excluded due to incomplete treatment, 6 were lost to follow-up, and 1 had a different histological type of tumor, namely basal 
cell carcinoma. Therefore, a total of 93 patients were analyzed in the present study. The patient characteristics are summarized in Table I. Staging evaluation was performed by digital rectal examination, MRI, CT and bone scintigraphy.

Risk stratification. In risk classification of prostate cancer (Table II), patients with all low-risk factors were classified as low-risk; those with any high-risk factor as high-risk; and those with any other combination as intermediate-risk. Complete androgen blockade (CAB) was performed from 6 months prior to PBT for intermediate- or high-risk cases, and patients at high risk continued $\mathrm{CAB}$ for 3 years. No combination therapy was used for low-risk cases based on our criteria.

Radiotherapy systems. The PBT system consisted of a 250 $\mathrm{MeV}$ synchrotron equipped with an isocentric rotational gantry, a $15 \times 15-\mathrm{cm}$ passive scattering port with a $5-\mathrm{mm}$ multileaf collimator, a rotational treatment couch, and a treatment-planning system (Hitachi 3D Treatment Planning System ver. 2.0; Hitachi Ltd., Tokyo, Japan) with a CT scanner and an X-ray simulator without any modifications. Dose volume histogram (DVH) parameters were calculated using the same treatment-planning system.

Principles of treatment planning. Target volume and risk organs were defined as follows: The clinical target volume (CTV) was set as the prostate plus $1 / 3$ caudal seminal vesicle (whole seminal vesicle for cT3b). The planning target volume (PTV) was defined as the CTV plus a $10-\mathrm{mm}$ lateral, $12-\mathrm{mm}$ anterior, and 5-mm craniocaudal and posterior margins. The rectum was contoured from the sigmoid flexure to the anus or ischial tuberosity, whichever was closer to the PTV. Low-risk cases received 74 GyE (relative biological effectiveness=1.1) in 37 fractions, and intermediate- or high-risk cases received $78 \mathrm{GyE}$ in 39 fractions. To reduce the dose to the rectum, the posterior edge of the PTV was set in front of the anterior wall of the rectum by using multileaf collimators after 30 fractions. Two lateral ports (one from either side) were used for treatment. Dose constraints to the rectum were set to the following: V50 $<30 \%, \mathrm{~V} 80<20 \%$ and $\mathrm{V} 90<10 \%$, although exceptions were permitted when the risk/benefit ratio was considered clinically acceptable. Dose constraints to the bladder were not set, since this was not an issue due to the beam angle set-up.

Patient preparation and fixation. Prior to treatment planning, the patients had fiducial markers installed in their prostate by a transrectal method for positioning verification. Image-guided patient position verification was performed using orthogonal $\mathrm{X}$-ray images for every fraction. In order to control bladder volume, the patients were asked to completely void their bladders 30 min prior to treatment and to drink one cup $(\sim 100 \mathrm{ml})$ of tea. Bladder volume was confirmed to be $\sim 100 \mathrm{ml}$, immediately prior to treatment using ultrasonic bladder volume measuring instruments. Fixation was performed using foot and leg rests without thermal plastic shells.

Follow-up. Regular follow-up included physical examinations and prostate-specific antigen (PSA) blood tests at 3- to 4-month intervals for the first 2 years and at 3- to 6-month intervals thereafter. Treatment-related morbidities were evaluated by physical examination and imaging. Events were assessed using the National Cancer Institute Common Terminology Criteria for Adverse Effects, version 4 (https://evs.nci.nih. gov/ftp1/CTCAE/CTCAE_4.03_2010-06-14_QuickReference_ 5x7.pdf).

Statistical analysis. Statistical analysis was performed using $\mathrm{R}$ software (http://www.r-project.org/). Gray analysis with death as a competing risk consideration was used for biochemical relapse-free rate and cumulative toxicity event rate calculations. Fine-Gray analysis was used for uni- and multivariate analysis. A P-value of $<0.05$ was considered to indicate statistically significant differences.

\section{Results}

Follow-up and outcome. The median follow-up time was 55 months (range, 32-97 months). All patients apart from one were PSA failure-free and the 5-year cumulative biochemical relapse-free rate was $99.0 \%$ (95\% CI: 93.2-99.9\%). Only one death was reported, which was due to pancreatic cancer. As regards late GU morbidity, grade 3 non-infectious cystitis occurred in 1 patient (1.5\%) and grade 2 urinary frequency and hematuria were observed in $4(4.3 \%)$ and $1(1.5 \%)$ patients, respectively. As regards late GI morbidity, grade 2 rectal bleeding was observed in 4 patients (4.3\%). No other grade $\geq 2$ adverse events were observed. The 5 -year cumulative incidence of grade $\geq 2 \mathrm{GU}$ and GI morbidities was 5.8 and $4.3 \%$, respectively (Fig. 2). The median maximum dose to the PTV was $101.5 \%[ \pm 0.21 \%$ two standard deviations (2SD)] of the prescribed dose. The median rectal V30 to V80 in 10\% increments were $32.5 \%( \pm 16.2 \% 2 \mathrm{SD}), 28.0 \%( \pm 17.9 \%), 23.8 \%$ $( \pm 13.4 \%), 20.0 \%( \pm 11.9 \%), 16.5 \%( \pm 10.4 \%)$ and $12.5 \%( \pm 8.6 \%)$, respectively. The rectal doses in patients with and without grade 2 GI toxicity are shown in Table III. All doses were higher in patients with grade 2 GI toxicity, but the difference was not statistically significant. On multivariate analysis, the use of anticoagulants was a significant positive risk factor [hazard ratio $(\mathrm{HR})=5.72,95 \%$ confidence interval $(\mathrm{CI})$ : 1.31-24.92] and the PTV volume was a significant negative risk factor (HR=0.96, 95\% CI: $0.937-0.983$ ) for grade 2 rectal bleeding. Age, Gleason score, initial PSA, prescription dose, and T3b disease were not found to be significant.

\section{Discussion}

Late toxicity following radiotherapy for prostate cancer has been a major concern from the start of use of this therapy (10). The emergence of 3D-CRT demonstrated that a high radiation dose to the target leads to better biochemical disease-free survival $(4,5,11)$, but is also associated with higher toxicity $(4,5)$. Several studies have investigated risk factors associated with late toxicities following radiotherapy for prostate cancer, and the irradiation dose and volume to the rectum and use of anticoagulants are considered to be key factors $(1,3,12,13)$.

The use of IGRT is also known to improve the actual dose to the rectum and, therefore, improve clinical results (14). A significant decrease in rectal toxicity was observed with the use of IGRT for high-dose irradiation (15). 
Table I. Patient characteristics.

\begin{tabular}{lc}
\hline Characteristics & No. $(\%)$ \\
\hline Age, years & \\
Median (range) & $68(49-81)$ \\
T stage & \\
T1c & $24(26)$ \\
T2a-T2b & $30(32)$ \\
T2c & $11(12)$ \\
T3a & $20(22)$ \\
T3b & $7(8)$ \\
T4 & $1(1)$ \\
Initial PSA value (ng/ml) & \\
$<10.0$ & $47(51)$ \\
$10.0-19.9$ & $21(23)$ \\
$\geq 20.0$ & $25(27)$ \\
Gleason score sum & \\
$\leq 6$ & $14(15)$ \\
7 & $33(35)$ \\
$\geq 8$ & $46(49)$ \\
Tumor risk group & \\
High & \\
Intermediate & $53(89)$ \\
Low & $32(35)$ \\
Antithrombotic drugs & $7(8)$ \\
Yes & \\
\hline No & $10(11)$ \\
\hline & \\
\hline & \\
\hline &
\end{tabular}

PSA, prostate-specific antigen.

Table II. Risk classification for treatment in our institution.

\begin{tabular}{lcc}
\hline Factors & Low-risk & High-risk \\
\hline T stage & T1c-2b & T3a-b, T4 \\
iPSA $(\mathrm{ng} / \mathrm{ml})$ & $<10.0$ & $\geq 20.0$ \\
Gleason score sum & $\leq 6$ & $\geq 8$ \\
\hline
\end{tabular}

Low-risk, all low-risk factors; high-risk, any high-risk factor; intermediate-risk, any other combination. iPSA, initial prostate-specific antigen.

Charged particle beams, such as those used in PBT, deliver high radiation doses to the target in a conformal manner, which minimizes the doses to OARs. This is realized by the unique fundamental physical characteristics known as Bragg peak, and by modulating it with the use of spread-out Bragg peak and collimators $(8,16)$. Alongside adequate re-planning, as described earlier, our rectal doses where lower compared with all parameters in other 3D-CRT studies $(1,17)$. Also, compared with IMRT studies, the high doses were comparable, and the intermediate doses were lower (18). Bladder doses have not been evaluated in detail; however, since we only utilized lateral irradiation ports ( 2 ports, Fig. 1), a low to intermediate dose to the bladder was sufficiently low.
Table III. Dose volume histogram comparison with and without late toxicity.

\begin{tabular}{lllllll}
\hline & \multicolumn{2}{c}{ Grade $<2$} & & \multicolumn{2}{c}{ Grade 2} & \\
\cline { 2 - 3 } Dosimetry & $\%$ & 2 2SD & & $\%$ & 2SD & P-value \\
\hline V30 & 33.6 & \pm 16.3 & & 37.3 & \pm 13.6 & 0.37 \\
V40 & 28.9 & \pm 15.0 & & 32.2 & \pm 12.0 & 0.387 \\
V50 & 24.8 & \pm 13.6 & & 27.9 & \pm 10.0 & 0.365 \\
V60 & 20.8 & \pm 12.1 & & 23.4 & \pm 8.0 & 0.394 \\
V70 & 16.9 & \pm 10.5 & & 19.3 & \pm 6.1 & 0.365 \\
V80 & 12.5 & \pm 7.7 & & 14.0 & \pm 4.6 & 0.497
\end{tabular}

2SD, two standard deviations.

As regards clinical results, with the use of fiducial markers and daily IGRT, grade 2 rectal bleeding developed in 4 patients $(4.3 \%)$, grade $\geq 2$ hematuria was observed in 2 patients $(2.1 \%)$ and grade 2 urinary frequency occurred in 4 patients (4.3\%). No other grade $\geq 2$ late adverse events were observed. Rectal toxicity was comparable with that of IMRT and lower compared with that of 3D-CRT, and genitourinary toxicity was better compared with that of both 3D-CRT and IMRT (Table IV) (7,19-30).

Unfortunately, due to the low toxicity incidence rate, the availability of statistical analysis data on risk factors of GI toxicity is limited. Patients with grade 2 GI toxicity had higher V30 to V80 rectal doses, but the difference was not significant. On multivariate analysis, the use of anticoagulants was the only significant positive risk factor, and PTV volume was a negative risk factor. Age, Gleason score, initial PSA, prescription dose and T3b disease were not significant factors, and these findings did not change after excluding PTV volume in the analysis. DVH analysis revealed higher doses, although without a significant difference, in patients with grade 2 GI toxicity, which is consistent with previous studies reporting rectal dose as a risk factor $(1,3)$. The DVH parameters likely failed to be significant due to the low event rate, with only 4 patients suffering grade 2 rectal bleeding, including 2 who received anticoagulant therapy. A larger PTV volume was not found to be a risk factor for GI toxicity, in contrast to findings supporting that a large PTV volume is a positive risk factor in other modalities (31). In addition to the low grade 2 incidence rate, this may be explained by our irradiation method. The PTV volume is enlarged by prostate hypertrophy and $\mathrm{T} 3 \mathrm{~b}$ disease, thus affecting the rectal dose. PBT is known to deliver a lower dose to the rectum and bladder, particularly in high-risk cases where seminal vesicle irradiation is required $(32,33)$, which supports the results of the present study.

GU toxicity was relatively low compared with that in previous reports. We consider this to be due to the conformal dose distribution in passive PBT. Heterogeneity of the radiation dose within the target is reported to predispose patients to urethral strictures (34). The maximum dose in the present study was $101.5 \%( \pm 0.21 \% 2 \mathrm{SD})$ of the prescribed dose, which is a difficult value to achieve using IMRT or scanning 
Table IV. List of previous reports on the results of treatment for prostate cancer.

\begin{tabular}{|c|c|c|c|c|c|c|c|c|c|}
\hline \multirow[b]{2}{*}{ First author } & \multirow[b]{2}{*}{ Method } & \multirow[b]{2}{*}{ Dose (Gy) } & \multirow[b]{2}{*}{ Gy/Fr } & \multicolumn{2}{|c|}{ 5-year BFS (\%) } & \multirow[b]{2}{*}{ High } & \multicolumn{2}{|c|}{$\begin{array}{l}\text { Grade } \geq 2 \\
\text { toxicity }^{\mathrm{a}}\end{array}$} & \multirow[b]{2}{*}{ (Refs.) } \\
\hline & & & & Low & Intermediate & & GI & GU & \\
\hline D'Amico & 3D-CRT & $66-70$ & 2 & 80 & $65-75$ & 40 & N/A & N/A & (19) \\
\hline Dearnaley & 3D-CRT & 74 & 2 & 85 & 79 & 57 & 43 & 15 & (20) \\
\hline Vora & 3D-CRT & $66-71$ & $1.8-2$ & 76 & 50 & 35 & 16 & 22 & (21) \\
\hline Zepatero & 3D-CRT & $76-82$ & 2 & N/A & 88 & 88 & 10.1 & 9.9 & (7) \\
\hline Zelefsky & IMRT & 81 & 1.8 & 85 & 76 & 72 & 1.8 & 12.2 & (22) \\
\hline Kupelian & IMRT & 70 & 2.5 & 94 & 83 & 72 & 1.8 & 12.2 & (23) \\
\hline Vora & IMRT & $70.2-77.4$ & 1.8 & 88 & 70 & 60 & 24 & 29 & (21) \\
\hline Cahlon & IMRT & 70 & 2.5 & 94 & 83 & 72 & 6 & 7 & (24) \\
\hline Martin & IMRT & 79.8 & 1.77 & 88 & 77 & 78 & 13.7 & 12.1 & (25) \\
\hline Guckeznberger & IMRT & 73.9-76.2 & 2.3 & 88 & 80 & 78 & 4.8 & 22.4 & (26) \\
\hline Schulte & PBT & 74-75 & $1.8-2$ & & 82 & & 3.5 & 5.4 & (27) \\
\hline Mendenhall & PBT & $78-82$ & 2 & 99 & 99 & 76 & 1.0 & 0.9 & (28) \\
\hline Takagi & PBT & 74 & 2 & 99 & 91 & 86 & 3.8 & 1.9 & (29) \\
\hline Bryant & PBT & $72-82$ & 2 & 94 & 88 & 88 & N/A & N/A & (30) \\
\hline Present study & PBT & $74-78$ & 2 & & 99 & & 5.4 & 1.0 & \\
\hline
\end{tabular}

${ }^{a}$ Late toxicity only. BFS, biochemical relapse-free survival rate; GI, gastrointestinal; GU, genitourinary; PBT, proton beam therapy; IMRT, intensity-modulated radiotherapy; 3D-CRT, 3-dimensional conformal radiotherapy; N/A, not available.
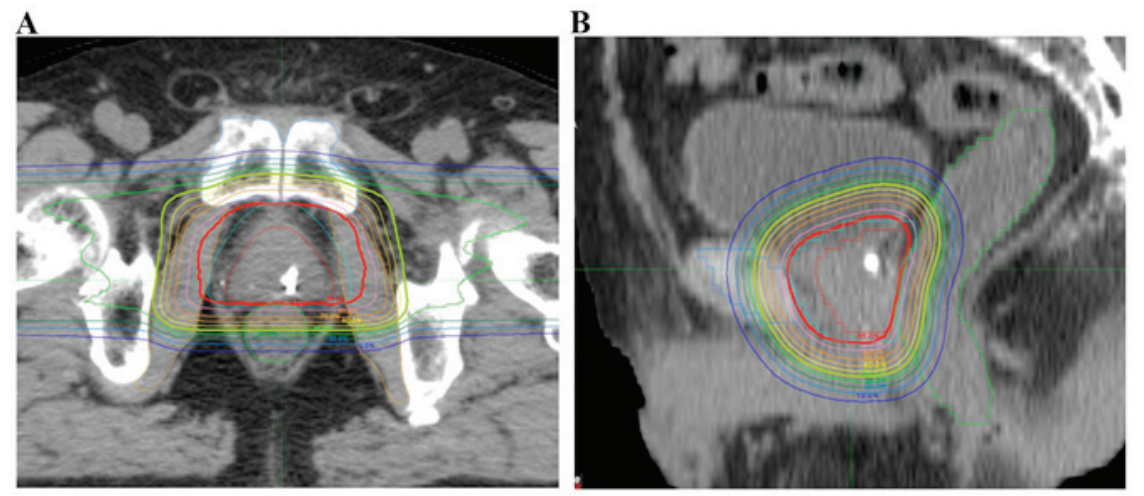

Figure 1. Typical dose distribution for the treatment of prostate cancer using proton beam therapy: (A) Axial and (B) sagittal view.

A

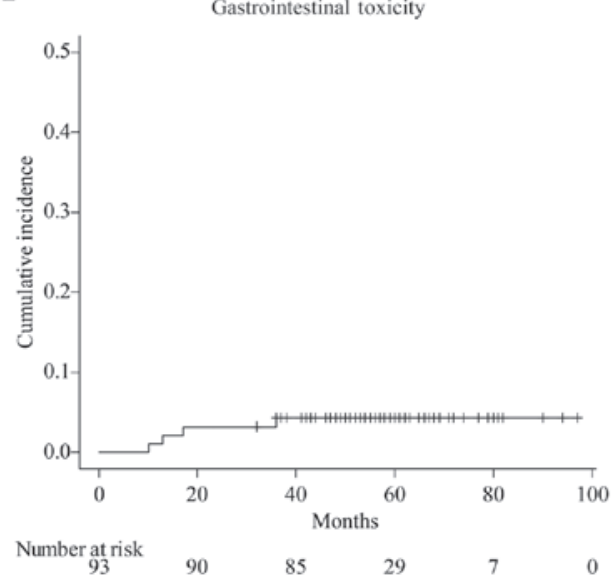

B

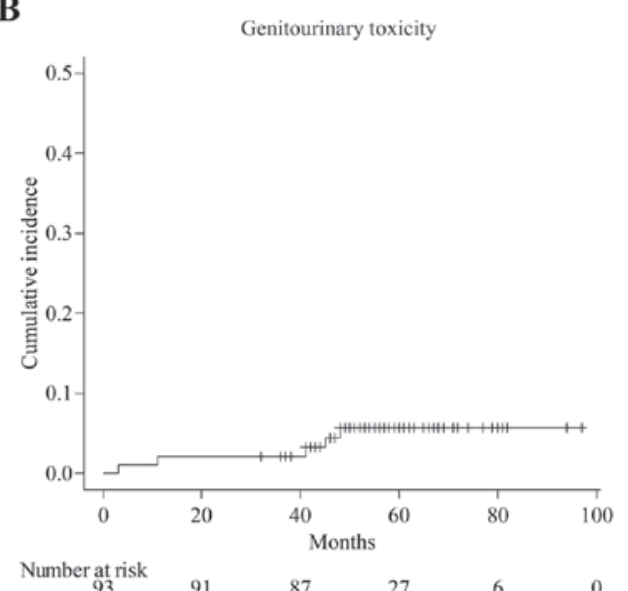

Figure 2. Cumulative (A) gastrointestinal and (B) genitourinary adverse events of grade $\geq 2$. 
PBT (35). This conformal dose may be an explanation for the low GU toxicity. Also, as discussed above, only lateral beams were used in PBT for prostate cancer, thus lowering the low to intermediate doses to the bladder.

Various approaches have been assessed to decrease late toxicity in prostate cancer treatment. Hypofractionation is considered to decrease the biological effective dose to the rectum due to the nature of prostate cancer, although extreme hypofractionation may result in compromising tumor control due to the heterogeneity of cancer (36). The use of carbon-ion radiotherapy is a more straightforward method for improving dose distribution with promising results, although it requires specialized equipment and a vast amount of space $(3,37)$.

The biological effectiveness of PBT is considered to be slightly higher compared with that of high-voltage $\mathrm{X}$-ray/cobalt-60, raising the relative biological effectiveness to 1.1 (38). This $10 \%$ change in biological effectiveness may contribute to better tumor control, but it is unclear without a randomized control study to evaluate such detailed difference. In the present study, all patients but one were PSA failure-free and the 5-year cumulative biochemical relapse-free rate was $99.0 \%$. Considering that the follow-up period was relatively short, with a median follow-up of just under 5 years, it is difficult to suggest better tumor control compared with other treatments, but the results appear to be promising. In addition, all the patients were observed for $>48$ months, which is sufficient for toxicity analysis, and the observed toxicities were minimal. We consider these results as promising, and PBT may be considered as a treatment option for prostate cancer. To elucidate the advantage of PBT over X-ray therapy, multiple prospective multi-center single-arm trials are currently underway.

\section{References}

1. Fiorino C, Sanguineti G, Cozzarini C, Fellin G, Foppiano F Menegotti L, Piazzolla A, Vavassori V and Valdagni R: Rectal dose-volume constraints in high-dose radiotherapy of localized prostate cancer. Int J Radiat Oncol Biol Phy 57: 953-962, 2003.

2. Sheets NC, Goldin GH, Meyer AM, Wu Y, Chang Y, Stürmer T, Holmes JA, Reeve BB, Godley PA, Carpenter WR and Chen RC: Intensity-modulated radiation therapy, proton therapy, or conformal radiation therapy and morbidity and disease control in localized prostate cancer. JAMA 307: 1611-1620, 2012.

3. Ishikawa H, Tsuji H, Kamada T, Hirasawa N, Yanagi T, Mizoe JE, Akakura K, Suzuki H, Shimazaki J and Tsujii H: Risk factors of late rectal bleeding after carbon ion therapy for prostate cancer. Int J Radiat Oncol Biol Phys 66: 1084-1091, 2006.

4. Michalski J, Winter K, Roach M, Markoe A, Sandler HM, Ryu J, Parliament M, Purdy JA, Valicenti RK and Cox JD: Clinical outcome of patients treated with 3D conformal radiation therapy (3D-CRT) for prostate cancer on RTOG 9406. Int J Radiat Oncol Biol Phys 83: e363-e370, 2012.

5. Michalski JM, Bae K, Roach M, Markoe AM, Sandler HM, Ryu J, Parliament MB, Straube W, Valicenti RK and Cox JD: Long-term toxicity following 3D conformal radiation therapy for prostate cancer from the RTOG 9406 phase I/II dose escalation study. Int J Radiat Oncol Biol Phys 76: 14-22, 2010.

6. Pollack A, Zagars GK, Starkschall G, Antolak JA, Lee JJ, Huang E, von Eschenbach AC, Kuban DA and Rosen I: Prostate cancer radiation dose response: Results of the M. D. Anderson phase III randomized trial. Int J Radiat Oncol Biol Phys 53: 1097-1105, 2002.

7. Zapatero A, Guerrero A, Maldonado X, Alvarez A, Gonzalez San Segundo C, Cabeza Rodríguez MA, Macias V, Pedro Olive A, Casas F, Boladeras A, et al: High-dose radiotherapy with short-term or long-term androgen deprivation in localised prostate cancer (DART01/05 GICOR): A randomised, controlled, phase 3 trial. Lancet Oncol 16: 320-327, 2015.
8. Pedroni E, Bacher R, Blattmann H, Böhringer T, Coray A, Lomax A, Lin S, Munkel G, Scheib S, Schneider U, et al: The $200-\mathrm{MeV}$ proton therapy project at the Paul Scherrer Institute: Conceptual design and practical realization. Med Phys 22: 37-53, 1995.

9. Zietman AL, DeSilvio ML, Slater JD, Rossi CJ Jr, Miller DW, Adams JA and Shipley WU: Comparison of conventional-dose vs high-dose, conformal radiation therapy in clinically localized adenocarcinoma of the prostate: A randomized controlled trial JAMA 294: 1233-1239, 2005

10. Horwitz EM and Hanks GE: External beam radiation therapy for prostate cancer. CA Cancer J Clin 50: 349-375; quiz 376-379, 2000.

11. Zelefsky MJ, Leibel SA, Gaudin PB, Kutcher GJ, Fleshner NE, Venkatramen ES, Reuter VE, Fair WR, Ling CC and Fuks Z: Dose escalation with three-dimensional conformal radiation therapy affects the outcome in prostate cancer. Int J Radiat Oncol Biol Phys 41: 491-500, 1998.

12. Akimoto T, Katoh H, Kitamoto Y, Tamaki T, Harada K, Shirai K and Nakano T: Rectal bleeding after high-dose-rate brachytherapy combined with hypofractionated external-beam radiotherapy for localized prostate cancer: Impact of rectal dose in high-dose-rate brachytherapy on occurrence of grade 2 or worse rectal bleeding. Int J Radiat Oncol Biol Phys 65: 364-370, 2006.

13. Fenwick JD, Khoo VS, Nahum AE, Sanchez-Nieto B and Dearnaley DP: Correlations between dose-surface histograms and the incidence of long-term rectal bleeding following conformal or conventional radiotherapy treatment of prostate cancer. Int J Radiat Oncol Biol Phys 49: 473-480, 2001.

14. Schaly B, Bauman GS, Song W, Battista JJ and Van Dyk J: Dosimetric impact of image-guided 3D conformal radiation therapy of prostate cancer. Phys Med Biol 50: 3083-3101, 2005.

15. Zelefsky MJ, Kollmeier M, Cox B, Fidaleo A, Sperling D, Pei X, Carver B, Coleman J, Lovelock M and Hunt M: Improved clinical outcomes with high-dose image guided radiotherapy compared with non-IGRT for the treatment of clinically localized prostate cancer. Int J Radiat Oncol Biol Phys 84: 125-129, 2012.

16. Inada T, Hayakawa Y, Tada J, Takada Y and Maruhashi A: Characteristics of proton beams after field shaping at PMRC. Med Biol Eng Comput 31 Suppl: S44-S48, 1993.

17. Jackson A, Skwarchuk MW, Zelefsky MJ, Cowen DM, Venkatraman ES, Levegrun S, Burman CM, Kutcher GJ, Fuks Z, Liebel SA and Ling CC: Late rectal bleeding after conformal radiotherapy of prostate cancer. II. Volume effects and dose-volume histograms. Int J Radiat Oncol Biol Phys 49: 685-698, 2001.

18. Pederson AW, Fricano J, Correa D, Pelizzari CA and Liauw SL: Late toxicity after intensity-modulated radiation therapy for localized prostate cancer: An exploration of dose-volume histogram parameters to limit genitourinary and gastrointestinal toxicity. Int J Radiat Oncol Biol Phys 82: 235-241, 2012.

19. D'Amico AV, Whittington R, Malkowicz SB, Cote K, Loffredo M, Schultz D, Chen MH, Tomaszewski JE, Renshaw AA, Wein A and Richie JP: Biochemical outcome after radical prostatectomy or external beam radiation therapy for patients with clinically localized prostate carcinoma in the prostate specific antigen era. Cancer 95: 281-286, 2002.

20. Dearnaley DP, Sydes MR, Graham JD, Aird EG, Bottomley D, Cowan RA, Huddart RA, Jose CC, Matthews JH, Millar J, et al: Escalated-dose versus standard-dose conformal radiotherapy in prostate cancer: First results from the MRC RT01 randomised controlled trial. Lancet Oncol 8: 475-487, 2007.

21. Vora SA, Wong WW, Schild SE, Ezzell GA and Halyard MY; Analysis of biochemical control and prognostic factors in patients treated with either low-dose three-dimensional conformal radiation therapy or high-dose intensity-modulated radiotherapy for localized prostate cancer. Int J Radiat Oncol Biol Phys 68: 1053-1058, 2007.

22. Zelefsky MJ, Chan H, Hunt M, Yamada Y, Shippy AM and Amols H: Long-term outcome of high dose intensity modulated radiation therapy for patients with clinically localized prostate cancer. J Urol 176: 1415-1419, 2006.

23. Kupelian PA, Willoughby TR, Reddy CA, Klein EA and Mahadevan A: Hypofractionated intensity-modulated radiotherapy ( $70 \mathrm{~Gy}$ at $2.5 \mathrm{~Gy}$ per fraction) for localized prostate cancer: Cleveland Clinic experience. Int J Radiat Oncol Biol Phys 68: 1424-1430, 2007.

24. Cahlon O, Zelefsky MJ, Shippy A, Chan H, Fuks Z, Yamada Y, Hunt M, Greenstein S and Amols H: Ultra-high dose (86.4 Gy) IMRT for localized prostate cancer: Toxicity and biochemical outcomes. Int J Radiat Oncol Biol Phys 71: 330-337, 2008. 
25. Martin JM, Bayley A, Bristow R, Chung P, Gospodarowicz M, Menard C, Milosevic M, Rosewall T, Warde PR and Catton CN: Image guided dose escalated prostate radiotherapy: Still room to improve. Radiat Oncol 4: 50, 2009.

26. Guckenberger M, Lawrenz I and Flentje M: Moderately hypofractionated radiotherapy for localized prostate cancer: Long-term outcome using IMRT and volumetric IGRT. Strahlenther Onkol 190: 48-53, 2014

27. Schulte RW, Slater JD, Rossi CJ Jr and Slater JM: Value and perspectives of proton radiation therapy for limited stage prostate cancer. Strahlenther Onkol 176: 3-8, 2000.

28. Mendenhall NP, Hoppe BS, Nichols RC, Mendenhall WM Morris CG, Li Z, Su Z, Williams CR, Costa J and Henderson RH: Five-year outcomes from 3 prospective trials of image-guided proton therapy for prostate cancer. Int J Radiat Oncol Biol Phys 88: 596-602, 2014.

29. Takagi M, Mima M, Terashima K, Fujii O, Demizu Y, Nagano F, Jin D, Okimoto T, Waki T, Murakami M and Fuwa N: Long-term outcomes in patients treated with proton therapy for localized prostate cancer. Int J Radiat Oncol Biol Phys 93: E186-E187, 2015.

30. Bryant C, Smith TL,Henderson RH, Hoppe BS, Mendenhall WM, Nichols RC, Morris CG, Williams CR, Su Z, Li Z, et al: Five-year biochemical results, toxicity and patient-reported quality of life after delivery of dose-escalated image guided proton therapy for prostate cancer. Int J Radiat Oncol Biol Phys 95: 422-434, 2016.

31. Vargas C, Yan D, Kestin LL, Krauss D, Lockman DM, Brabbins DS and Martinez AA: Phase II dose escalation study of image-guided adaptive radiotherapy for prostate cancer: Use of dose-volume constraints to achieve rectal isotoxicity. Int J Radiat Oncol Biol Phys 63: 141-149, 2005.

32. Rana S, Cheng C, Zheng Y, Risalvato D, Cersonsky N, RamirejE, Zhao L, Larson G and Vargas C: Proton therapy vs. VMAT for prostate cancer: A treatment planning study. International Journal of Particle Therapy 1: 22-33, 2014.
33. Rana S, Cheng C, Zhao L, Park S, Larson G, Vargas C, Dunn M and Zheng Y: Dosimetric and radiobiological impact of intensity modulated proton therapy and RapidArc planning for high-risk prostate cancer with seminal vesicles. J Med Radiat Sci 64: $18-24,2017$

34. McDonald AM, Baker CB, Popple RA, Cardan RA and Fiveash JB: Increased radiation dose heterogeneity within the prostate predisposes to urethral strictures in patients receiving moderately hypofractionated prostate radiation therapy. Pract Radiat Oncol 5: 338-342, 2015.

35. Tran A, Zhang J, Woods K, Yu V, Nguyen D, Gustafson G, Rosen L and Sheng K: Treatment planning comparison of IMPT, VMAT and $4 \pi$ radiotherapy for prostate cases. Radiat Oncol 12: 10, 2017.

36. Krauss DJ, Ye H, Martinez AA, Mitchell B, Sebastian E, Limbacher A and Gustafson GS: Favorable preliminary outcomes for men with low- and intermediate-risk prostate cancer treated with 19-Gy single-fraction high-dose-rate brachytherapy. Int J Radiat Oncol Biol Phys 97: 98-106, 2017.

37. Kasuya G, Ishikawa H, Tsuji H, Nomiya T, Makishima H, Kamada T, Akakura K, Suzuki H, Shimazaki J, Haruyama Y, et al: Significant impact of biochemical recurrence on overall mortality in patients with high-risk prostate cancer after carbon-ion radiotherapy combined with androgen deprivation therapy. Cancer 122: 3225-3231, 2016.

38. Paganetti H, Niemierko A, Ancukiewicz M, Gerweck LE, Goitein M, Loeffler JS and Suit HD: Relative biological effectiveness (RBE) values for proton beam therapy. Int J Radiat Oncol Biol Phys 53: 407-421, 2002. 